\title{
Enterobacter cloacae ulceration in a failed corneal graft: a case report
}

\author{
NEIL D GROSS AND ROGER F MEYER
}

From the Department of Ophthalmology, University of Michigan Medical School, Ann Arbor, Michigan, USA

SUMMARY A 70-year-old female developed a bacterial ulcer in a previously rejected corneal graft. Cultures identified the pathogen as Enterobacter cloacae. Intensive topical antibiotic therapy arrested the progress of the ulcer, and the epithelial defect healed in one week; there was no resultant stromal thinning. Factors which may have predisposed the cornea to ulceration by this organism of relatively low virulence include chronic oedema following graft rejection, topical corticosteroid therapy, and tear insufficiency.

Bacterial corneal ulcers pose a serious threat to the eye. Bacterial keratitis may be caused by both Grampositive and Gram-negative organisms. Gram-positive organisms most commonly causing keratitis include Staphylococcus aureus, Streptococcus pneumoniae, and Str. viridans. Gram-negative corneal ulcers are most frequently caused by Pseudomonas aeruginosa, Moraxella lacunata, and Serratia marcescens. ${ }^{1}$ Occasionally genera of the family Enterobacteriaceae such as Klebsiella cause corneal ulceration. ${ }^{2} \mathrm{~A}$ case of corneal ulceration due to Enterobacter cloacae, the first published report, is presented to underscore the importance of this unusual ocular pathogen.

\section{Case report}

A 70-year-old female with anterior cortical cataracts underwent extracapsular cataract extraction and anterior chamber intraocular lens implantation of the left eye in January 1977. The eye subsequently developed posterior capsule opacification and cystoid macular oedema. In 1978 she was referred for treatment of pseudophakic bullous keratopathy. Visual acuity in the left eye was light perception. Her entire cornea was oedematous with epithelial bullae and stromal oedema, with folds. The endothelium was not visible. An Optical Radiation Corporation anterior chamber intraocular lens implant was in place. Behind the lens was a dense membrane adherent to the edge of the pupil with a white

Correspondence to Roger F Meyer, MD, WK Kellogg Eye Center, University of Michigan, 1010 Wall Street, Ann Arbor, Michigan 48105, USA. horizontal band through the visual axis. Corneal sensation was markedly decreased. Schirmer testing with anaesthesia was $8 \mathrm{~mm}$ and $4 \mathrm{~mm}$, OD and OS respectively. She underwent penetrating keratoplasty with an $8.5 \times 8.0 \mathrm{~mm}$ graft, pars plana vitrectomy, and excision of the pupillary membrane in September 1978.

Five years later she developed an acute endothelial graft rejection, which was treated by topical steroid therapy. The inflammatory episode subsided, but the graft remained oedematous, with epithelial microbullous changes, mild punctate staining, and persistent stromal oedema. She continued to use fluorometholone drops four times daily.

In January 1984 she reported a three-day bout of epiphora, foreign body sensation, and swelling of the left eyelid. On examination visual acuity of the left eye was hand motions at 6 inches $(15 \mathrm{~cm})$. There was slight erythema of the left upper lid with mild swelling. The cornea had microbullous epithelial changes and a $3.0 \times 1.2 \mathrm{~mm}$ epithelial defect with an underlying dense, white stromal infiltrate which was paracentrally located in the oedematous corneal transplant. A small hypopyon was present inferiorly (Fig. 1).

The patient was admitted to the WK Kellogg Eye Center and treated intensively with topical bacitracin $(10000$ units $/ \mathrm{ml})$ and fortified gentamicin $(13.6 \mathrm{mg} / \mathrm{ml})$ drops to alternate every 15 minutes around the clock. The FML drops were tapered and discontinued over a three-day period.

Gram stain revealed Gram-negative bacilli. Cultures showed Enterobacter cloacae, verified by 


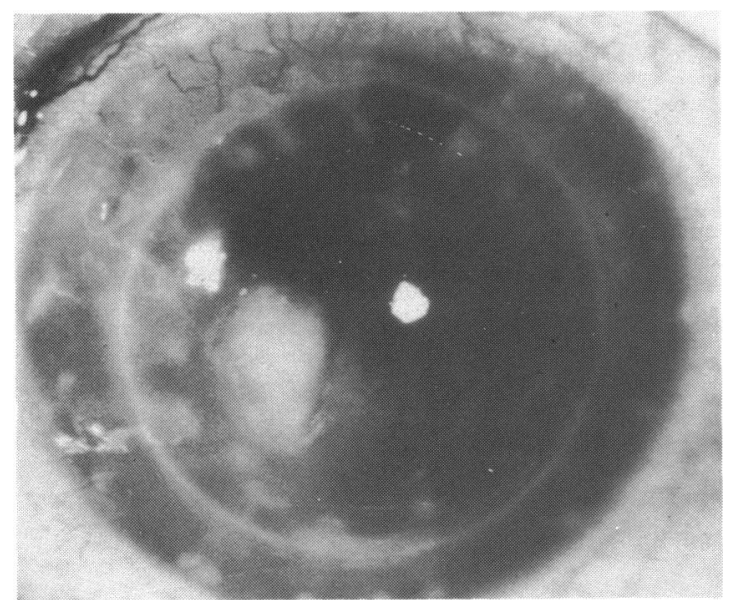

Fig. 1 Pretreatment appearance of E. cloacae corneal ulcer is shown.

the Analytical Profile Index system. The organism was sensitive to gentamicin, tobramicin, and sulphacetamide; it was resistant to bacitracin.

On treatment day 2, when cultures revealed Enterobacter cloacae, sulphacetamide 15\% drops were substituted for bacitracin. On the fourth treatment day the infiltrate was diminished, and the frequency of drop instillation was tapered. On treatment day 7 the epithelial defect had healed. At the time of discharge from the hospital the corneal epithelium was intact and the stroma was minimally scarred. There was residual oedema secondary to previous graft rejection. There was no significant stromal thinning.

\section{Discussion}

Corneal ulceration solely due to Enterobacter cloacae has not been previously reported in the literature. One case of endophthalmitis ascribed to this organism was noted by Rose and Koch in $1966 .{ }^{3}$ Enterobacter cloacae and Actinobacter calcoaceticus have been isolated in several cases of acute polymicrobial conjunctivitis. ${ }^{4}$ Recently Boisjoly et al. reported a case of corneal superinfection by this organism in a patient with recurrent herpes simplex keratitis. ${ }^{5}$

Until the mid 1960s Enterobacter cloacae was not considered to be an important pathogen anywhere in the body. It was thought to be an organism which primarily colonised the gastrointestinal tract but was not responsible for disease. Recently clinicians have begun to recognise its virulence. John et al. noted that Enterobacter cloacae was present in $4-12 \%$ of all cases of Gram-negative bacteraemia. ${ }^{\circ}$ It has also been implicated in endocarditis, meningitis, septic arthritis, urinary tract infection, pneumonia, and pelvic inflammatory disease. ${ }^{6}$

The importance of host defences has been widely recognised, and organisms previously considered to be non-pathogenic have become important vectors of disease in patients whose immune systems are compromised. In John and colleagues' series burn patients were cited as being at high risk for developing Enterobacter cloacae bacteraemia. ${ }^{\circ}$

In the eye the corneal epithelium is recognised as an important barrier against infectious keratitis. Besides providing a physical barrier to the entry of bacteria into the stroma' intact epithelium may actively phagocytise bacteria in response to chemotactic stimuli. ${ }^{8}$ Tears also protect the eye by mechanically washing away micro-organisms. Tear film IgA facilitates opsonisation and may also inhibit adherence of bacteria to ocular mucosa. Other components of tears, such as lysozyme, are bactericidal..$^{\prime \prime \prime \prime}$

Impairment of normal ocular defences may leave the eye more vulnerable to attack by pathogens. For example, studies have shown that persistent defects in the corneal epithelium increase the risk of corneal ulceration and perforation." Concomitant topical steroid therapy may also exacerbate ulceration. ${ }^{12} 13$

The patient presented in this report may have been particularly at risk for corneal ulceration by Enterobacter cloacae because of impairment of local host defences. The corneal epithelial barrier had been disrupted by chronic oedema following a previous episode of graft rejection, decreased tear production, and long-term topical corticosteroid therapy. It is likely that the patient directly introduced this stoolbased organism into the eye by means of poor toilet hygiene and inadequate hand washing.

Fortunately the infection was controlled by topical sulphacetamide and gentamicin drops. Enterobacter cloacae is usually resistant to ampicillin and can produce a cephalosporinase which may deactivate some cephalosporins. ${ }^{14}$ Aminoglycosides have been the most effective drugs against the organism and sepsis has been treated with carbenicillin and an aminoglycoside. ${ }^{15}$ However, there have not been any organised clinical trials to delineate the most efficacious regimen for treatment of systemic or ocular infections caused by Enterobacter cloacae.

This work was supported by the Michigan Eye Bank Research Fund.

\section{References}

1 Wilson LA. Bacterial Corneal Ulcers. In: Duane TD, ed. Clinical ophthalmology. 4th ed. Philadelphia: Harper and Row, 1984: 1-2.

2 Grayson M. Diseases of the cornea. Mosby, St Louis: 1983: 48.

3 Rose HD, Koch ML. Hospital acquired Aerobacter cloacae infections. Arch Intern Med 1966; 117: 92-8. 
4 Hatano H, Hirayama N, Ohki K, Naziizumi H. Polymicrobial infection in acute conjunctivitis. Folia Ophthalmol Jpn 1981; 32: 2173-7.

5 Boisjoly HM, Pavan-Langston D, Kenyon KR, Baker AS. Superinfections in herpes simplex keratitis. Am J Ophthalmol 1983; 96: 354-61.

6 John JF Jr, Sharbaugh RJ, Bannister ER. Enterobacter cloacae: bacteremia, epidemiology and antibiotic resistance. Rev Infect Dis 1982; 4: 13-28.

7 Hazlett LD, Rosen D, Berk RS. Experimental eye infection caused by Pseudomonas aeruginosa. Ophthalmic Res 1976; 8: 311-8.

8 Zimianski MC, Dawson CR, Toqui B. Epithelial cell phagocytosis of Listeria monocytogenes in the conjunctiva. Invest Ophthalmol Visual Sci 1974; 13: 623-6.

9 Dawson CR. How does the external eye resist infection? Invest Ophthalmol Visual Sci 1971; 15: 971-3.
10 Tiffany JM, Bren AJ. The role of tears in maintaining.corneal integrity. Trans Ophthalmol Soc UK 1978; 98: 335-8.

11 Cavanaugh HD, Pihlaju D, Thoft RD, Dohlman CH. The pathogenesis and treatment of persistent epithelial defects. Trans Am Acad Ophthalmol Otolaryngol 1976: 81: 754-69.

12 Brown SI, Weller CA, Vidrich AM. Effect of corticosteroids on corneal collagenase of rabbits. Am J Ophthalmol 1970; 70: 744-7.

13 Francois J, Cambie E, Feher J, et al. Pencillamine in the treatment of alkali burned corneas. Ophthalmic Res 1973; 4: 223-7.

14 Neu HC, Winshell EB. Relation of beta-lactamase activity and cellular location to resistance of Enterobacter to penicillins and cephalosporins. Antimicrob Agents Chemother 1972; 1: 107-11.

15 Dhawan V, Marso E, Martin WJ, Young LS. In vitro studies with netilmicin compared with amikacin, gentamicin and tobramicin. Antimicrob Agents Chemother 1977; 11: 64-73. 